\title{
Carbon Emission Estimation of Prefabricated Buildings Based on Life Cycle Assessment Model
}

\author{
Wenfang Zhou \\ Department of Engineering Management, School of Urban Construction Engineering, Wenhua College, Wuhan 430074, \\ China \\ †Corresponding author: Wenfang Zhou; whut_zwf@126.com
}

Nat. Env. \& Poll. Tech.

Website: www.neptjournal.com

Received: 05-08-2020

Revised: $31-10-2020$

Accepted: 02-12-2020

Key Words:

Prefabricated buildings

Carbon emission

Energy conservation

Emission reduction

\begin{abstract}
As a typical secondary industry in China, the building industry promotes China's construction and development significantly. The urban construction scale is expanding continuously with the increase of the urbanization rate. However, resources needed for construction and influences of construction on the ecological environment are enormous, which further cause resource consumption and environmental destructions. Therefore, changing the traditional mode of construction and promoting the development of prefabricated buildings vigorously are conducive to realize the goal of environmental protection and resource conservation. In this study, a life cycle assessment model for prefabricated buildings was constructed based on the basic data of resource and energy consumption in the production stage, transportation stage, and field installation stage. The total carbon emission of a prefabricated building in Wuhan City was estimated, and specific energy conservation and emission reduction measures were proposed. Results show that prefabricated buildings have become a major manifestation of the industrialization of construction, represented by America, Germany, and Japan. In the case study, the total carbon emission of prefabricated components in the project is $3277.66 \mathrm{t}$, in which the carbon emissions in the production stage, transportation stage, and field installation stage account for $86.58 \%$, $12.37 \%$, and $1.05 \%$, respectively. Based on the above research results, the further decrease in carbon emissions of prefabricated buildings by promoting the development of building energy efficiency and prefabricated buildings, accelerating R\&D and innovation of prefabricated building technologies, and strengthening training to designers related with installation of prefabricated buildings is suggested. Research conclusions have important significance in various aspects, such as providing case-based references and guidance to the carbon emission reduction of prefabricated buildings and supply basic data to decrease carbon emission caused by the production of building materials, developing new environmentally friendly materials to relieve the impact of carbon emissions from the building industry on the environment, realizing energy conservation and emission in the field of construction, and promoting the sustainable development of prefabricated buildings.
\end{abstract}

\section{INTRODUCTION}

Human productivity has increased significantly after the industrial revolution. However, the blind pursuit of economic development has caused excessive consumption of earth resources and serious damage to the ecological environment. China's economy achieves rapid development. As an important department of material production, the building industry also has undergone rapid development. The construction and operation of the building industry are human activities that incur the maximum natural resource consumption. The rapid development of the building industry brings considerable resource and energy consumption and serious environmental pollution when it promotes national economic development and improves the quality of life of people. In addition to severe environmental and economic situations, the traditional building industry is also facing many social problems, such as low labour productivity and lack of technological innovation. Moreover, enterprises have to pay for the continuously increasing labour cost, low recovery and high recovery cost of building materials, and considerable emissions of construction wastes because of the intensifying ageing of the population and the vanishing demographic dividends in China, thus restricting the sustainable development of the building industry in the social dimension significantly. Understanding how to decrease carbon emission in the construction and development of low-carbon buildings is needed during building industrial development in a low-carbon society.

Recently, the building industry in Hubei Province has developed rapidly. The total output value (100 million Yuan) of the building industry and floor spaces under construction $\left(10,000 \mathrm{~m}^{2}\right)$ in $2010-2019$ were increasingly quickly (Fig. 1). The annual growth rates reached $32.31 \%$ and $29.72 \%$, respectively. Such rapid development of the building 
industry has brought considerable pressures over the environment. Hubei Province entered into the list of low-carbon pilot provinces in 2010. As the capital of Hubei Province, Wuhan City has also been making great efforts to lower energy consumption in the building industry to comply with the construction needs of low-carbon pilot cities. The " 13 th Five-year Plan" Outline for Building Industrial Development in Hubei Province stipulated explicitly that the energy-saving standard for new residential buildings is increased from $50 \%$ to $65 \%$. Thus, prefabricated buildings will be a dominant trend in the building industry. Prefabricated buildings refer to buildings that are assembled at a construction site by several components that had been prefabricated or semi-prefabricated in factories. In this background, prefabricated buildings are highly appreciated for their high production efficiency, short construction period, small resource consumptions, and low environmental pollution. Moreover, many enterprises are promoting prefabricated buildings under the guidance of relevant policies and innovating assembly technologies concerning energy conservation and environmental protection, aiming to improve environmental-friendly performance of the buildings and promote sustainable development of the building industry. Prefabricated buildings are an important way to develop environmental-friendly buildings in China at present. Studying the environment-friendly performance of prefabricated buildings throughout the life cycle is conducive for the promotion of the development of China's building industry toward green buildings and the relief of resource wastes and environmental pollution in the building industry.

\section{EARLIER STUDIES}

Energy consumption during the construction of buildings is increasing yearly and is accompanied by serious environmental pollution. These are related to the largescaled unreasonable use of concrete and steel and backward construction technologies. Improved energy-saving efficiency of buildings is one of the best methods for developing prefabricated buildings. Prefabricated buildings have been studied extensively in foreign developed countries because of the environment-friendly construction mode, the factorization of prefabricated component production, design standardization, the informatization of engineering management, and decoration integration. Concerning the carbon emission of prefabricated buildings and the realization of energy-saving and emission reductions, Gerwick pointed out at the annual conference of PCI (Precast/Prestressed Concrete Institute) in 1991 that the development of prefabricated concrete structures was a new opportunity for the building and industrial development in the United States and even worldwide and that the United States was one of the countries that studied prefabricated buildings early. Moreover, they proposed that prefabricated concrete buildings and steel buildings mainly focused on large and medium-sized cities (Gerwick 1991). Jaillon et al. believed that the building industry in Hong Kong depended on traditional field construction to a large extent and that the wet industry uses extensive applications of wood templates. They also discussed the sustainable development of prefabricated structures in high-rise buildings. Results have shown that, compared with traditional buildings, prefabricated buildings have significantly higher environmental, economic, and social benefits (Jaillon et al. 2008). Pons et al. analysed prefabricated buildings from the perspective of technology and sustainable development to determine how prefabricated buildings improve their quality

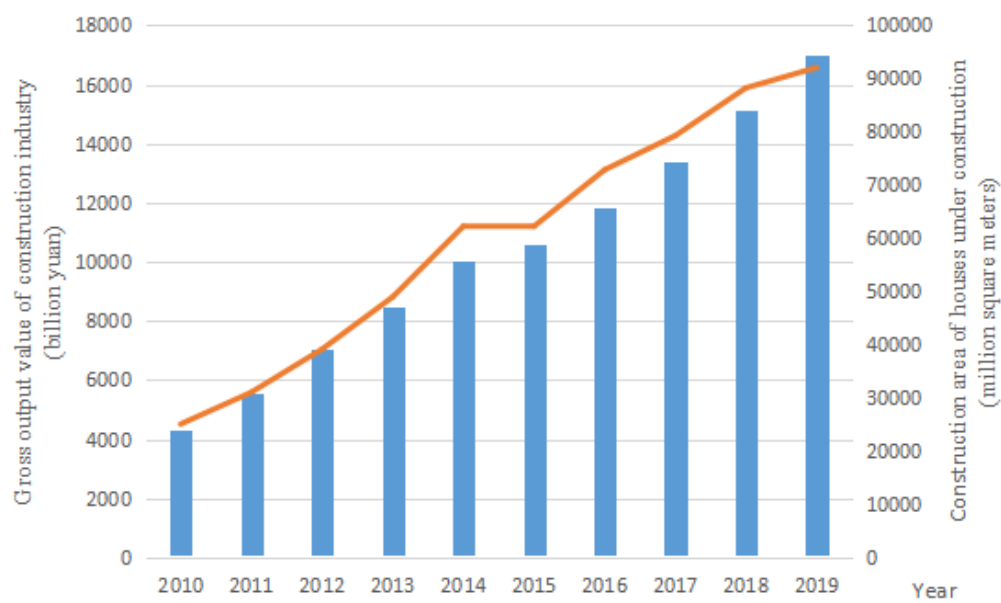

Fig. 1: Total output value (100 million Yuan) and floor spaces under construction (10,000 $\left.\mathrm{m}^{2}\right)$ of the building industry in Hubei Province in $2010-2019$. 
and decrease their influences on the environment. Carbon emission differences between industrialized technologies and the non-prefabricated technology were compared using the full life cycle assessment (LCA), which has proven that prefabricated buildings can decrease resource consumption and waste production (Pons et al. 2011). Aye et al. carried out quantitative analysis on the energy-saving effects of multiple modularized prefabricated steel and wood residential buildings and found that prefabricated steel structures could decrease as much as $78 \%$ of material consumption compared with traditional concrete structures (Aye et al. 2012). Mao et al. analysed the calculation boundaries and five emission sources during the construction of prefabricated buildings, constructed a quantitative model based on the process, and carried out a preliminary study on the differences of greenhouse gas emissions between a semi-prefabricated project and a conventional architectural project in China. They concluded that the greenhouse gas emission per square meter in the semi-prefabricated project was lower than that of the conventional architectural project (Mao et al. 2013). Based on the theory of full life cycle, Lu W. et al. carried out an empirical study on carbon emissions during the manufacturing and cross-border transportation of precast slabs, assessed the potential of precast slabs in decreasing wastes, and proposed specific measures to decrease carbon emissions (Lu et al. 2013). Bonamente et al. investigated carbon emission and energy footprints in the Italian prefabricated building department performed parametric estimation on greenhouse gas emission and energy consumptions in different stages of the life cycle of buildings and proposed measures to decrease carbon emissions of the building industry (Bonamente et al. 2014). Dong et al. compared carbon emissions of prefabricated construction and traditional cast-in-situ construction based on a private residential building in Hong Kong and established the LCA model. The results show that the carbon emission of this residential building was equal to $669 \mathrm{~kg} \mathrm{CO}_{2}$ per square meter and that the prefabricated concrete structure could decrease its carbon emission per cubic meter by $10 \%$ (Dong et al. 2015). Based on two typical residential buildings, Cao et al. combined the construction environmental performance assessment system based on LCA and building health impact assessment system to evaluate the energy consumptions of prefabricated construction technology and conventional construction technology. They concluded that prefabricated buildings had high energy utilization, and the total energy consumption decreased by $20.49 \%$ (Cao et al. 2015). Hong et al. believed that prefabricated structure was an effective strategy to increase the production efficiency of the building industry. Using a case study based on practical prefabricated buildings, He discussed energy use throughout the life cycle of prefabricated components and effects of prefabricated components on total energy use. Results demonstrated that prefabricated buildings could control energy saving by decreasing waste production and improving quality, and it saved energy consumption by $4-14 \%$ in the whole life cycle (Hong et al. 2016). Hong et al. established a cost-benefit analysis framework and discussed the basic cost composition of a prefabricated construction project. According to research results, key attention should be paid to promote the development of prefabricated construction technologies and optimize the structural integrity of prefabricated components in the future to develop their economic benefits fully (Hong et al. 2018). Ling et al. evaluated the environmental impact of a temporary house with a renewable energy source system and constructed an LCA model for each stage. Moreover, the LCA model for a temporary residential building oriented to carbon emission reduction was proposed, which was conducive to promote the sustainable development of prefabricated temporal residential buildings (Ling et al. 2018). Hossain et al. evaluated the wood waste management system using the LCA model from the perspective of environmental protection and concluded that influences of chipboard and wood-cement composite, which were made of wood waste composite on the environment, were relieved significantly (Hossain et al. 2018). The above literature review shows that, in foreign developed countries, especially the USA, Germany, and Japan, the prefabricated construction technological system is well developed, and the energy-saving technologies are more mature. In particular, prefabricated buildings have become a major manifestation of building industrialization in economically developed countries. According to the literature review, prefabricated buildings can bring social progress in standardization, high efficiency, and sustainable development. However, prefabricated buildings still face various challenges against promotion in China because of a shortage of cost, technologies, and management. In this study, the carbon emissions of a prefabricated building in Wuhan City, Hubei Province, China in the production stage, transportation stage, and installation stage were estimated by the LCA model, and specific energy conservation and emission reduction measures were proposed.

\section{MODELS}

Life cycle assessment (LCA) is a research methodology that evaluates the influences of a product on the environment throughout its life cycle. LCA has been extensively applied in various fields, including engineering, material, and equipment. The LCA model is composed of the determination of objective and scope, list analysis, impact assessment, and result analysis. 


\section{OBJECTIVE AND SCOPE}

The research objective is to compare carbon emissions of components of prefabricated buildings in different stages based on the carbon emission estimation of LCA theory and analyze carbon emission sources and major influencing factors in different stages of the life cycle. A prefabricated building involves various types of components in different sizes. For the convenience of comparison, the unit volume $\left(1 \mathrm{~m}^{3}\right)$ was chosen as the evaluation index of one functional unit, which could evaluate carbon emission relatively accurately.

\section{List Analysis}

List analysis is a process of data acquisition and reviewing, and it is the key and foundation of LCA. Based on classification statistics of data concerning material consumption, mechanical consumption, and component transportation in different life stages of prefabricated building, all data related with carbon emission factors of different materials and energy sources were collected into a list for further processing and computing. This list is called the list of life cycle.

\section{Carbon Emission Calculation Model}

Carbon emission mainly refers to emissions of greenhouse gases represented by $\mathrm{CO}_{2}$ and accompanied by $\mathrm{CH}_{4}$ and $\mathrm{N}_{2} \mathrm{O}$. The International Energy Agency unified emissions of various greenhouse gasses into $\mathrm{CO}_{2}$ equivalent $\left(\mathrm{CO}_{2}\right.$-eq) for quantitative analysis on carbon emission. Carbon emission sources that may exist during construction, service and waste stages in life cycle prefabricated buildings are listed in Table 1.

Table 1: Carbon emission sources in the building industry.

\begin{tabular}{|ll|}
\hline Stages & Descriptions \\
\hline $\begin{array}{l}\text { Production and pro- } \\
\text { cessing of prefabri- } \\
\text { cated components }\end{array}$ & $\begin{array}{l}\text { Carbon emissions from mining, production, and } \\
\text { transportation of raw materials to the prefabricated } \\
\text { component factory; carbon emissions from the } \\
\text { consumed resources and instruments used in the } \\
\text { production of prefabricated components; carbon } \\
\text { emissions from resource consumption during } \\
\text { transportation of prefabricated components; and } \\
\text { carbon emissions from energy consumption for } \\
\text { mechanical operation during the field assembly }\end{array}$ \\
$\begin{array}{l}\text { Transportation of } \\
\text { prefabricated com- } \\
\text { ponents }\end{array}$ & $\begin{array}{l}\text { Carbon emissions from resource consumption } \\
\text { Field installationsportation }\end{array}$ \\
& $\begin{array}{l}\text { Carbon emissions from the energy consumption } \\
\text { for the operation of construction equipment and } \\
\text { machines during the installation of prefabricated } \\
\text { components }\end{array}$ \\
\hline
\end{tabular}

According to Eq. (1), an LCA model of carbon emissions of a prefabricated building is the sum of $\mathrm{CO}_{2}$-eq of greenhouse gases in different stages.

$$
Q=Q_{m}+Q_{t}+Q_{c}
$$

Where $Q_{m}, Q_{t}$ and $Q_{c}$ are carbon emissions in the production and processing stage, transportation stage, and field installation stage of prefabricated components, respectively.

\section{Impact Assessment and Result Interpretation}

Impact assessment refers to the quantitative analysis and evaluation of environmental influences in different stages of a life cycle based on the list analysis data. Carbon emissions of different types of components in the life cycle and contributions of different components to carbon emissions in different life stages were analysed, aiming to determine key influencing factors and links of carbon emission. Impact assessment can provide basic data for the energy conservation and emission reduction of prefabricated buildings and offer a development direction for energy-saving buildings.

\section{CASE STUDY}

In this study, the carbon emission of a prefabricated building in Wuhan City throughout the life cycle was calculated. The selected prefabricated building for the case study covers a building area of approximately $67500 \mathrm{~m}^{2}$ and involves complete types of prefabricated components with a prefabrication rate of $63 \%$. Prefabricated components in the manufacturing factory were transported by heavy semitrailer tractors. These heavy semitrailer tractors have a carrying capacity of $30 \mathrm{t}$ and are loaded with diesel. The diesel consumption is $45 \mathrm{~L} / 100 \mathrm{~km}$. The project site is $57 \mathrm{~km}$ from the manufacturing factory. The main types of prefabricated components for prefabricated buildings include balcony clapboards, precast shear walls, precast infilled wall (external wall), precast infilled wall (internal wall), superposed slabs, superposed beams, balconies, and stairs. In this study, a statistical analysis of the material composition, production techniques, and energy consumption of prefabricated components in main prefabricated component factories in Wuhan City was carried out. Prefabricated components adopt flow line production, and electricity consumption is the sole mechanical energy consumption. Data in different stages were brought into the model, and carbon emissions in different stages were calculated according to Eq. (1). Results are shown in Table 2.

Table 2 shows that the total carbon emission of prefabricated components in the selected project throughout the life cycle reaches $3277.66 \mathrm{t}$, in which carbon emissions in the production stage, transportation stage, and field 
Table 2: Carbon emissions of prefabricated components in different stages.

\begin{tabular}{|llll|}
\hline $\begin{array}{l}\text { Prefabricated } \\
\text { components }\end{array}$ & $\begin{array}{l}\text { Carbon } \\
\text { emission in } \\
\text { the production } \\
\text { stage (T) }\end{array}$ & $\begin{array}{l}\text { Carbon emis- } \\
\text { sion in the } \\
\text { transportation } \\
\text { stage (T) }\end{array}$ & $\begin{array}{l}\text { Carbon } \\
\text { emission } \\
\text { in the field } \\
\text { installation } \\
\text { stage }(\mathrm{T})\end{array}$ \\
\hline Precast shear wall & 48.23 & 6.98 & 0.87 \\
Precast shear wall & 1567.27 & 182.33 & 17.23 \\
External wall & 347.92 & 76.81 & 4.45 \\
Internal wall & 179.35 & 40.91 & 2.98 \\
Superposed slabs & 367.34 & 63.12 & 4.29 \\
Superposed beams & 39.71 & 3.81 & 0.64 \\
Balconies & 198.29 & 20.16 & 2.16 \\
Stairs & 89.63 & 11.25 & 1.93 \\
Total & 2837.74 & 405.37 & 34.55 \\
\hline
\end{tabular}

installation stage contribute $86.58 \%, 12.37 \%$, and $1.05 \%$, respectively. The production stage is the key stage to decrease the carbon emission of prefabricated components. According to a refined analysis of the production process, carbon emission in the production stage mainly comes from carbon emissions that are produced by used building materials, and concrete and rebar are major carbon emission sources. Therefore, the decrease in waste of concrete and rebar during practical production should be given attention. Given that cement is the major component of concrete, a recommendation is to replace cement with superplasticizer during concrete manufacturing, which can increase the strength of prefabricated components and decrease carbon emissions from the source as much as possible. Steel materials are essential in construction. The utilization of materials shall be increased, and material wastes shall be decreased reasonably. When decreasing the waste of aluminium materials, alternative materials with a relatively small carbon emission factor can be used as embedded parts, which can decrease carbon emission significantly. Carbon emission in the transportation stage is related to the workload of prefabricated components and transportation distance. A suggestion is to choose prefabricated component factories near the project to decrease carbon emission in the transportation stage. In the production stage, the precast shear wall contributes to the maximum carbon emissions, followed by superposed beams. Carbon emission is great given that rebar consumption is large. In the field installation stage, carbon emission per cubic meter is related to the complexity of component installation. When complexity claims are high, mechanical energy consumption at installation and carbon emissions increase. Given the whole project, carbon emissions of different prefabricated components are related to workloads directly.

\section{ENERGY CONSERVATION AND EMISSION REDUCTION MEASURES}

\section{Promoting the Development of Building Energy-Saving Technologies and Prefabricated Buildings}

The building design level shall be improved. The use functions of buildings and requirements on energy-saving, watersaving, land-saving, material-saving, and environmental protection shall be highlighted. Economical, reasonable, safe, and reliable architectural design products with applicable functions, advanced technologies, and environmental harmony shall be provided. The government-invested public welfare buildings and indemnificatory housing, such as office buildings, schools, hospitals, and cultural buildings, shall execute green building standards. Regions with proper conditions are encouraged to execute green building standards completely. Moreover, green buildings have to be developed vigorously. Green construction shall be promoted from materials and techniques, and the leading support of the technological system shall be strengthened. It is suggested to strengthen modernized standard construction in the building industry; establish a fast transformation mechanism between technological innovations and technological standard systems; encourage and support social institutions and enterprises to compile their own standards for prefabricated buildings; and set up engineering construction standard systems for prefabricated building design, part production, construction, quality inspection, acceptance check, and evaluation.

\section{Accelerating Technological R\&D and Innovation for Prefabricated Buildings}

It is suggested to (1) set up a standard-based authentication mechanism to restrict projects and products to execute relevant standards strictly; (2) strengthen R \& D supports of key technologies; (3) perfect the government-industry-university research cooperative innovation mechanism; attach high attention to optimize new technological R \& D and application environment; summarize and promote advanced technological systems for different types of building products; (4) organize R\&D of renewable energy sources, new wall materials, external wall insulation, and energy-efficient doors and windows; (5) accelerate the transformation of mature building energy-saving and green building technologies to standards; (6) accelerate the promotion of the evaluation and labelling system for green buildings and green building materials; (7) build a provincial evaluation and labelling management information platform for green buildings and green building materials; (8) make independent and integrated evaluations to green building materials, techniques, 
technologies, and products; strengthen the integration of green construction technologies and materials; recommend overall evaluated green building product systems; and (9) implement bases of green building material industries and engineering application pilots in typical regions and projects.

\section{Strengthen Training to Assembly-Related Designers}

Training helps construction workers to deepen their understanding of the energy-saving design philosophy of prefabricated buildings and properties and the applications of thermal insulation materials. Specific training plans shall be formulated to field construction workers according to their job tasks to help them fully understand their jobs and importance, thus assuring the construction quality and further protecting the overall quality of the building. The systematic management of prefabricated component factories is needed, and relevant production standards and operation codes have to be published. Relevant departments shall make spot checks irregularly to implement conditions of manufacturing shop standards and norms, product quality, and production environment and perfect the supervision and leadership of sections at all levels. Prefabricated factories shall set up a quality inspection department to check the quality of raw materials and produce prefabricated components. Besides, factories shall set up a perfect management system for the component warehouse. Before the production, systematic training shall be provided to production workers, and an assessment system has to be formulated. Only workers who pass the assessment are allowed to participate in production activities.

\section{CONCLUSIONS}

The building industry consumes considerable natural resources and causes huge environmental pollution while promoting national economic development. As a $\mathrm{CO}_{2}$ emission power, China is facing great pressure in emission reduction. Understanding how to decrease carbon emission in the construction and development of low-carbon buildings are needed during building industrial development in a low-carbon society. In this study, the total carbon emissions caused by resource and energy consumption in the production stage, the transportation stage, and the field installation stage of a prefabricated building in Wuhan City were estimated. Results show that prefabricated buildings have become a major manifestation of the industrialization of construction, represented by America, Germany, and Japan. In the case study, the total carbon emission of prefabricated components in the project is $3277.66 \mathrm{t}$, in which carbon emissions in the production stage, transportation stage, and field installation stage account for $86.58 \%, 12.37 \%$, and $1.05 \%$, respectively. The above research results suggest the further decrease of carbon emissions of prefabricated buildings by promoting the development of energy-efficient and prefabricated buildings, acceleration of $\mathrm{R} \& \mathrm{D}$, the innovation of prefabricated building technologies, and strengthening the training of designers regarding the installation of prefabricated buildings. Further studies on the comparison of carbon emissions between prefabricated buildings and traditional buildings, the effects of prefabricated buildings on environmental and economic sustainable development, and the establishment of green evaluation system of prefabricated buildings are needed.

\section{REFERENCES}

Aye, L., Ngo, T., Crawford, R. H., Gammampila, R. and Mendis, P. 2012. Life cycle greenhouse gas emissions and energy analysis of prefabricated reusable building modules. Energy and Buildings, 47(47): 159-168.

Bonamente, E., Merico, M. C., Rinaldi, S., Pignatta, G., Pisello, A. L., Cotana, F. and Nicolini, A. 2014. Environmental impact of industrial prefabricated buildings: carbon and energy footprint analysis based on an LCA approach. Energy Procedia, 61: 2841-2844.

Cao, X., Li, X., Zhu, Y. and Zhang, Z. 2015. A comparative study of environmental performance between prefabricated and traditional residential buildings in China. Journal of Cleaner Production, 109(16): 131-143.

Dong, Y. H., Jaillon, L., Chu, P. and Poon, C. S. 2015. Comparing carbon emissions of precast and cast-in-situ construction methods - A case study of high-rise private building. Construction and Building Materials, 99: 39-53.

Gerwick, B. C. 1991. The global advance emerging opportunities at home and abroad. PCI Journal, 36(6): 32-37.

Hossain, M. U. and Poon, C. S. 2018. Comparative LCA of wood waste management strategies generated from building construction activities. Journal of Cleaner Production, 177(10): 387-397.

Hong, J., Shen, G. Q., Li, Z. and Zhang, B. 2017. Barriers to promoting prefabricated construction in China: A cost-benefit analysis. Journal of Cleaner Production, 172(1): 649-660.

Hong, J. K., Shen, G. Q., Mao, C., Li, Z. D. and Li, K. J. 2016. Life-cycle energy analysis of prefabricated building components: An input-outputbased hybrid model. Journal of Cleaner Production, 112: 2198-2207.

Jaillon, L. and Poon, C. S. 2008. Sustainable construction aspects of using prefabrication in dense urban environment: A Hong Kong case study. Construction Management \& Economics, 26(9): 953-966.

Lu, W. and Yuan, H. 2013. Investigating waste reduction potential in the upstream processes of offshore prefabrication construction. Renewable \& Sustainable Energy Reviews, 28(8): 804-811.

Ling, D., Yu, W. and Hong, L. Z. 2018. Carbon reduction measures-based LCA of prefabricated temporary housing with renewable energy systems. Sustainability, 10(3): 718.

Mao, C., Shen, Q. P., Shen, L. Y. and Tang, L. Y. 2013. Comparative study of greenhouse gas emissions between off-site prefabrication and conventional construction methods: Two case studies of residential projects. Energy and Buildings, 66(5): 165-176.

Pons, O. and Wadel, G. 2011. Environmental impacts of prefabricated school buildings in Catalonia. Habitat International, 35(4): 553-563. 